\title{
Novel Computerized Halal Pharmaceuticals Supply Chain Framework for Warehouse and Procurement
}

\author{
Raja Rina binti Raja \\ Ikram \\ Biomedical Computing and \\ Engineering Technologies \\ (BIOCORE) Applied Research \\ Group, \\ University Teknikal Malaysia \\ Melaka (UTeM).
}

\author{
Mohd Khanapi bin Abdul \\ Ghani \\ Biomedical Computing and \\ Engineering Technologies \\ (BIOCORE) Applied Research \\ Group, \\ University Teknikal Malaysia \\ Melaka (UTeM).
}

\author{
Abdul Samad Hasan \\ Basari \\ Biomedical Computing and \\ Engineering Technologies \\ (BIOCORE) Applied Research \\ Group, \\ University Teknikal Malaysia \\ Melaka (UTeM).
}

\begin{abstract}
Computerized systems and software technology are extensively used to enhance manufacturing and supply chain performance in the pharmaceutical industry. The halal pharmaceuticals industry is growing and more study is required to cater this evolving industry as technology progresses and advanced computerized systems are introduced in the manufacturing sector to increase productivity. Enforcement and religious authorities require a documented guideline to enforce halal certification whenever a manual operation is substituted by a computerized system. The current halal pharmaceuticals certification guidelines by enforcement agencies in Malaysia and Indonesia mainly focus on manual operations. This paper shall propose a framework to manage the halal supply chain when computerized systems are being used for the warehouse and procurement module. The proposed framework is the outcome of a case study of a Malaysian pharmaceutical organization, Pharmaniaga Manufacturing Berhad in Bangi, Selangor.
\end{abstract}

\section{General Terms}

Healthcare Informatics, Software Engineering, Software Requirements

\section{Keywords}

Halal, Pharmaceuticals, Computerized Systems

\section{INTRODUCTION}

The Halal industry is growing with a large international market and potential revenue of $\$ 632$ billion annually [1]. Thus, companies are not ready for true globalization if they do not serve the needs the halal market including halal pharmaceutical products. Computer and software technology are also extensively used to improve manufacturing and supply chain performance since the 1980s when United States Food and Drug Administration (FDA) published its first Regulatory Guideline on the usage of computerized systems [2]. This proves that international regulatory bodies have acknowledged that it is crucial to regulate computerized systems used for the pharmaceutical and healthcare industry for the past 30 years. Based on research efforts, the author has not managed to acquire other guidelines other than the Malaysian and Indonesian Halal Pharmaceuticals Guideline as reference for halal pharmaceuticals. However, both these guidelines do not address any rules for the usage of computerized systems to assist in halal compliance. This guideline is important to assist industry and religious authorities in enforcing halal certifications to ensure Muslims in the world can consume their health medications, supplements and pharmaceutical products peacefully whenever a manual operation is substituted by a computerized system [13].

This paper shall propose a framework to provide a guide for pharmaceutical industry personnel to ensure proper adherence to the halal requirements when computerized systems are being used in the warehouse and procurement unit of the pharmaceutical supply chain in the area of solid dosage manufacturing. This framework shall propose software requirements to manage the halal pharmaceutical supply chain and assist manufacturers to implement halal compliance whenever a computerized system is used to substitute a manual operation.

Before describing the proposed framework, this paper shall briefly explain the methodology of the framework. This paper then presents critical issues in the halal supply chain and pharmaceutical industry that pose restrictions of the requirements of the proposed framework. Then, the components of the proposed framework is defined and discussed in detail and the validation results are elaborated. Finally, the conclusions and suggestions for research are addressed.

\section{METHODOLOGY}

This research was conducted in a Malaysian pharmaceutical organisation, Pharmaniaga Manufacturing Berhad. Subject matter experts or industry personnel from the warehouse and procurement units whose work routine relate directly with the usage of Enterprise Resource Planning (ERP) system was selected to participate in a semi structured questionnaire regarding pharmaceutical and halal related processes. A prototype application of the proposed framework was developed and validated by the participants. The participants' assessment of the prototype application was captured in a structured questionnaire to measure their acceptance towards the proposed framework.

\section{HALAL SUPPLY CHAIN}

Halal is derived from an Arabic word which means allowed or permissible according to Islamic law [3]. The basic principles of halal includes thoyyiban (wholesome) taken from Al Quran verse 168 of Surah Al Baqarah. Thoyyiban indicates quality, 
safety, cleanliness and nutritious [4]. Thus halal and thoyyiban signifies hygiene, safety and quality [4]. The concept of halal food encompasses the Islamic lawful requirements and requirements for quality food in terms of hygiene, sanitation and safety [5]. Failure of any of these aspects will destroy the wholesomeness concept of halal food. It is estimated that $70 \%$ of world Muslims adhere to halal standards [1], implying its increasing importance to the food industry.

\subsection{Halal Pharmaceuticals}

Halal Pharmaceuticals is defined as pharmaceutical products that consist of ingredients that are permitted under shariah or Islamic religious law which do not contain ingredients that are non halal or ingredients that are derived from animals that are not slaughtered according to shariah law and safe for consumption. The product must not be prepared, processed, or manufactured using equipment contaminated by non halal items as defined is Islamic religious law. It also must not contain human part and derivatives and stored separately from products that are non halal [6]. Halal pharmaceuticals are a harmonization of shariah or Islamic religious law, Good Manufacturing Practice (GMP) standards and the approved halal supplier and material list [7]. The shariah or Islamic religious law requirements are aligned with the Good Manufacturing Practice requirements in order to produce the Halal Pharmaceuticals standard. These standards integrated with the approved list of halal ingredients used in production govern the whole halal pharmaceutical supply chain.

It is an organization's decision opt for halal certification for either individual products or all their pharmaceutical products that they manufacture as certification done is product based and not facility based because every product contain different materials or formulation which require individual assessment by halal auditors [8].

\subsection{Key Responsibilities for Warehouse and Procurement Units}

The implementation of halal supply chain require members from the management to be accountable for ensuring every process is controlled to avoid [8] non halal contamination. Members of the management consists of a few business units mainly procurement, warehouse, quality, production, asset management, human resource, finance and production planner [12]. The responsibility of the top management, warehouse and procurement unit can be summarized in the following points [8]:

\subsubsection{Top Management:}

The top management is responsible to formulate company policy related to halal compliance and fully support the implementation of halal assurance system in the organisation. They are responsible to provide necessary infrastructure and facility for the implementation of halal pharmaceuticals.

\subsubsection{Procurement:}

The procurement unit is responsible to establish a purchasing system to ensure consistency of raw materials purchased according to approved specifications, halal certificate and approved list of materials.

\subsubsection{Warehouse:}

The warehouse unit is responsible to establish a storage administration system to avoid contamination of haram or prohibited materials according to Islamic religious law.

\subsection{Key Issues for Halal Compliance}

The determination of halal compliance of ingredients and packaging materials used can be confirmed through halal certificate, declaration of halal compliance, material specifications, certificate of analysis and determination of manufacturing process [9]. To ensure the manufacturing process is halal compliant, the organization must comply with quality requirements and avoid cross contamination of halal and non halal products, utensils and equipment used [9]. It is also beneficial if the organization adopts other quality certifications such as Good Manufacturing Practice, Good Hygiene Practice, Environment and Safety Requirements.

Amongst the hazards identified in the halal pharmaceutical supply chain is contamination of haram or prohibited materials in warehouse, production lines and during distribution [8]. Other hazards issues include traceability of raw materials, qualification of halal materials, management of approved halal materials list, qualification of personnel, management of warehousing and procurement of approved materials [6]. Formulation of products also requires verification that the ingredients only contain halal materials before any product is allowed to be manufactured in the production lines [8].

Other critical issues in the halal supply chain include origin of raw materials, ingredients and additives, slaughtering method, contamination in processing operations and equipments, packaging, storage and transportation and emphasis on safety and quality aspects [9]. The source of materials used in the manufacturing process is critical to determine the halal status of the final product. The method used to slaughter animals is required to comply with Islamic religious requirements to ensure the origin of animal derived ingredients used in the manufacturing of pharmaceutical product is halal to be consumed. The manufacturing process and equipments used is critical to ensure no contaminated materials are allowed in the manufacturing area and equipment used are continuously clean, or ritually cleaned before any production process is initiated. The packaging material source and specifications are required to be from non contaminated sources and is able to prevent contamination after the packaging process is completed. Storage and transportation conditions are also required to provide proper segregation of halal and non halal products to prevent contamination during warehousing and delivery of goods. The halal concept also emphasizes on safety and quality aspects of the product, in addition to the Islamic religious law requirements. This is to ensure the product consumed shall not pose any health hazards when consumed.

\section{PHARMACEUTICAL INDUSTRY RESTRICTIONS}

The pharmaceutical industry has several restrictions which has been taken into consideration when developing this framework.

\subsection{Good Manufacturing Practice (GMP)}

The pharmaceutical industry is governed by strict GMP regulations that are compulsory to be adhered to before any pharmaceutical manufacturer can be licensed to produce for commercial sale. GMP requires pharmaceutical companies to have appropriate documentation to support their manufacturing and control processes [10] with emphasizing high risk to processes that have direct impact to product quality. The key issue is validation which requires proof that any procedure, process, equipment, material, activity or system leads to the expected result [10]. Computer Validation 
is part of the validation required that is inspected by pharmaceutical authorities to qualify the plant from manufacturing pharmaceuticals. Thus our proposed framework shall need to comply with these restrictions with sufficient documented validation evidence before any system goes live.

\subsection{Other Restrictions}

In addition to the GMP requirements, the pharmaceutical industry is also practises other additional requirements such as Good Distribution Practice (GDP) [2] and Good Laboratory Practice (GLP) [11]. Critical issues within these requirements related to usage of computerized systems are procedural and security controls, disaster recovery, design, data processing capacity, calibration and maintenance [2].

\section{PROPOSED WAREHOUSE FRAMEWORK}

This section shall propose the computerised controls framework to manage the halal pharmaceutical supply chain in the warehouse module.

\subsection{Framework Overview}

Warehouse and Logistics module consists of three main functions - receiving of materials, storage, and inventory issuance outgoing from warehouse including distribution to customers according to Figure 1.

\subsubsection{Warehouse Receiving}

One major warehouse function is receiving of materials such as materials for production, returned goods from customers, and also finished goods from production waiting to be delivered to customers. Every item received is required to have a traceable identification and the halal status of the item can be identified from the system at the point of receiving. The system need to ensure material received matches the material may be ordered from different manufacturers and each material has to be checked for its halal qualification, which can vary for different manufacturers.

\subsubsection{Warehouse Storage}

After receiving the items, it is then stored in the dedicated locations either quarantine, and released locations. These locations also have dedicated storage for halal items to ensure segregation with other materials. The locations these items are stored - i.e. rack, storage room - can also be accessed in the system and shall be immediately identifiable as dedicated halal locations. A computerised trigger shall be enforced where halal items shall be prevented to be moved to a non halal storage area. This is to ensure segregation of materials are properly defined and to avoid contamination with non halal materials.

\subsubsection{Warehouse Issuance / Delivery:}

After items received are stored, another main warehouse function is to issue materials out to production for manufacturing, issue samples to quality for testing, delivery of goods to customers or return rejected materials to suppliers. The materials issued to production shall be able to be traced in the system from the original manufacturer lot to the finished goods batch. The finished batches produced shall also be traced to the distribution or sales point of the customer. This is to ensure products can be recalled or a proper investigation can be done when a complain is received from customers. A problem detected in a material used shall be traceable to different batches of different products produced to assess the product quality.

\subsection{Process Flow}

The process flow for the proposed warehouse framework is discussed in this section according to the flow order specified in Figure 1.

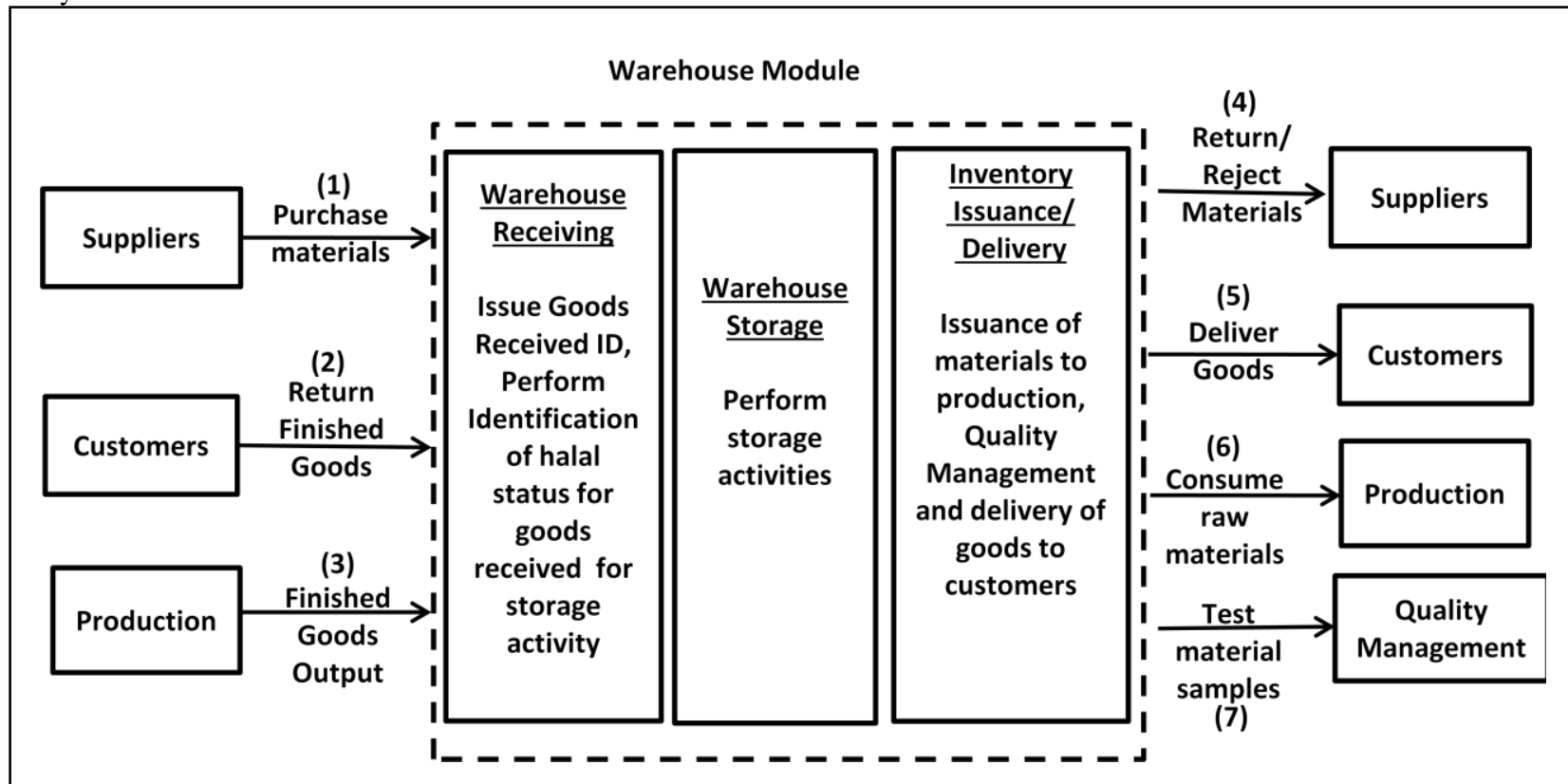

Fig 1: Proposed Warehouse Framework

information required and the system is expected to be able to automatic screen the halal qualification of materials based on the information of the items received.

Items or materials with different manufactures shall also be identified uniquely in the system. This is because the same
1. Purchase Materials: Items purchased from suppliers are received by warehouse. All items shall be checked for accurate information when received in order for the system to be able to screen qualified suppliers. 
2. Return Finished Goods: Incoming Finished Goods returned by customers are received by warehouse.

3. Finished Goods Output: Finished goods output from production are also received by warehouse while waiting for delivery to customers.

4. Return/Reject Materials: Materials rejected are issued out from warehouse and returned to suppliers or disposed.

5. Deliver Goods: Finished Goods that are approved for release shall be delivered to the customers.

6. Consume raw materials: Materials required for manufacturing shall be issued out to production floor.

7. Test Material Samples: Sample for quarantined materials or finished goods shall also be issued to quality management for testing.

\subsection{Key Issues}

The key requirements for a system to support the halal compliance of a warehouse management system is users are able to access and assign clear identification of storage locations (up to pallet level) to materials. In addition, to ensure that the materials stored are not mixed up in the wrong locations, clear identification of halal and non halal raw materials must exist. This information should be able to be accessed easily from the system to ensure daily operations can be executed accurately and timely as any contamination cases are highly risky and will affect operation schedule. Traceability of material usage and delivery is also important to ensure any complaints or halal status can be tracked to the batch or lot produced. This also enables a recall of the product to be done successfully with complete information of distribution address, quantity and lot information which is also part of pharmaceutical GMP requirements [14]. Other key halal compliance issues are traceability of usage and status of warehouse equipment and spare parts used to ensure clear segregation and identification of parts that have direct contact with halal and non halal materials or products. The warehouse unit is also responsible to ensure dedicated storage is available for halal transportation of incoming and outgoing goods.

\section{PROPOSED PROCUREMENT FRAMEWORK}

This section shall propose the computerized controls framework to manage the halal pharmaceutical supply chain in the procurement module.

\subsection{Framework Overview}

The main fuction of the procurement unit is to purchase materials based on the approved halal suppliers. These approved suppliers are configured in the system by the quality management personnel. A computerised control shall prevent a purchase order created for non approved materials. Any materials received can also be traced to the purchase orders generated together with manufacturer information. The procurement framework is referred to in Figure 2.

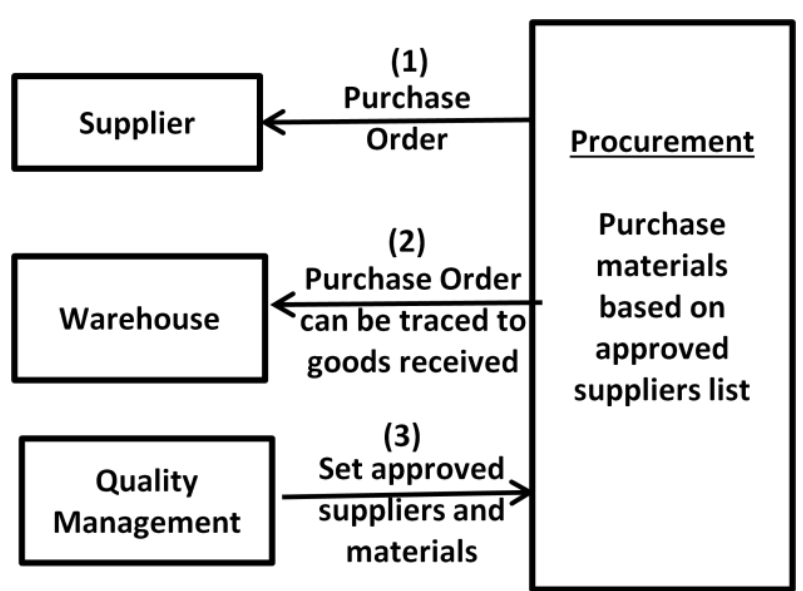

Fig. 2: Proposed Procurement Framework

\subsection{Process Flow}

The process flow for procurement framework shall be discussed in this section according to the flow order specified in Figure 2.

1. Purchase Order: Purchase orders are generated to suppliers based on the approved supplier list preconfigured in the system.

2. Traceability of Purchase Orders to Goods Received: Materials received by warehouse shall be traceable to the purchase order generated from the system together with manufacturer information.

3. Configuration of Approved Suppliers: Quality Management personnel configures and controls the approved supplier information in the system.

\subsection{Key Issues}

The main halal issues to support the purchasing system are traceability or audit trail, qualification of raw materials and manufacturers, and tracking of expired halal certificates. The tracking of expired halal certificates can be executed if there is a system trigger for expired halal certificates in the form of email or error messages if a user decides to consume the raw material in warehouse for production use. It is recommended to assign a quality check if the halal certificate is expired before the material is dispensed into production. Audit trails should also be made available to ensure complete traceability of material usage and prevent unauthorized information changes.

\section{VALIDATION RESULTS}

The participants were assessed on a few issues of the prototype Halal Computerised Risk Assessment for the Pharmaceuticals (HalCracs) application according to Figure 3. They were first measured on their assessment of the proposed framework before using HalCracs where the participants were briefed and provided instructions to rate their initial knowledge regarding management of halal supply chain via computerised systems. After testing HalCracs, the participants were required to reassess their knowledge on the proposed framework to analyse if there was an acceptance of the new computerised controls to assist them in managing halal compliance. They were then asked to measure their understanding of their role to contribute to the halal compliance in the organisation after testing HalCracs and also provide feedback on other graphical user interface functionalities. 


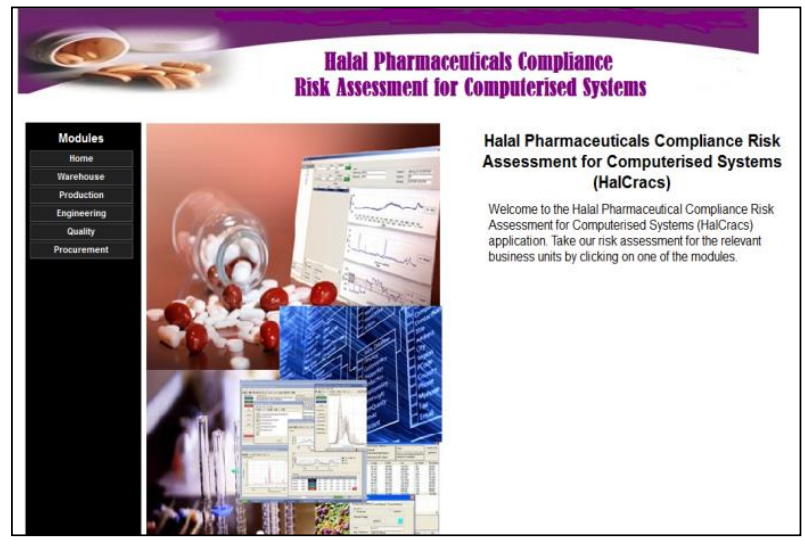

Fig. 3: Main user interface for HalCracs

The results of the assessment of HalCracs were very encouraging. All participants' feedback on their individual assessment of halal pharmaceuticals increased at least $10 \%$ after testing HalCracs in comparison with the score before testing the application with $80 \%$ of the participants showed an increase of at least $30 \%$ after using the prototype application. This shows that the proposed framework has relevance in their work routine since all participants are subject matter experts in the warehouse and procurement units in the organization. At least $80 \%$ of participants scored a minimum of $60 \%$ in the knowledge scale after testing HalCracs.

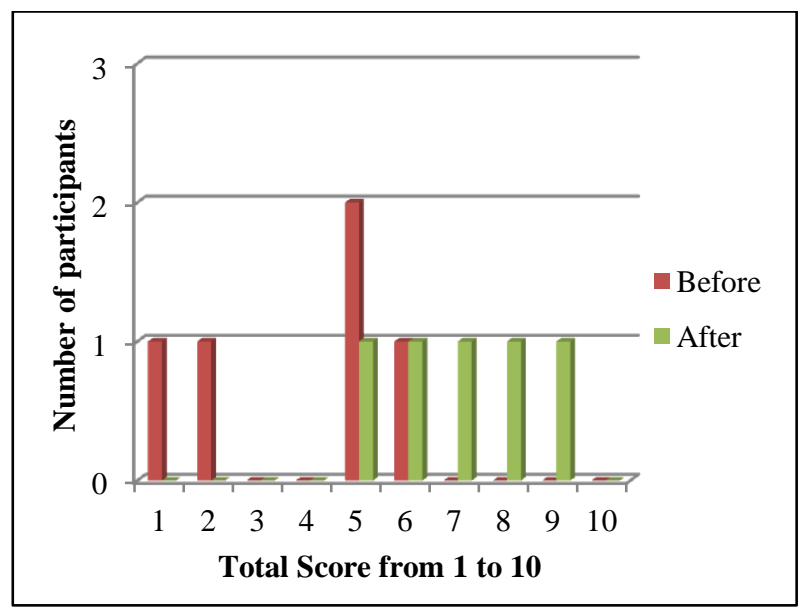

Fig. 4: Participants score before and after testing HalCracs

According to Figure 4, 4 out of 5 participants scored at least 6 out of 10 in the HalCracs assessment. From this, 1 out of 5 participants had an increase of 1 point, and 4 out of 5 participants had showed an increase of at least 3 points. This is an indication that the overall understanding in the organisation has increased with regards to halal compliance and the proposed framework is accepted by all the participants. The results of the questionnaire also show that $100 \%$ of the participants have rated at least $60 \%$ in measurement of their role understanding in managing the risk of non halal compliance in the organization.

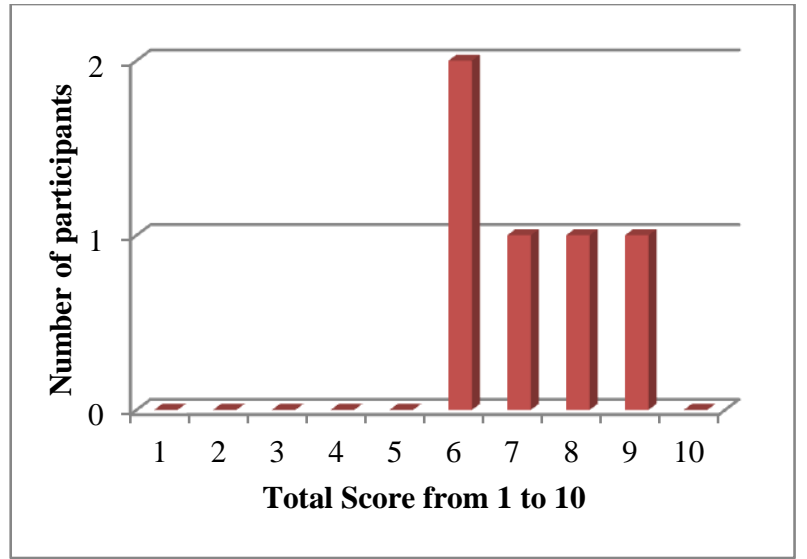

Fig. 5: Participants score on measurement of role understanding in managing halal supply chain

According to Figure 5, 2 out of 5 participants score at least 6 points and one participant had scored 7,8 and 9 points when assessing their role of understanding in managing the halal supply chain. This implies that the proposed framework is applicable to be implemented in the organisation's supply chain.

\section{CONCLUSION}

This paper has proposed a framework for computerised controls in the halal pharmaceutical supply chain for warehouse and procurement units based on a case study of a Malaysian pharmaceutical organisation, Pharmaniaga Manufacturing Berhad. In addition, pharmaceutical industry restrictions are also taken into consideration in the development of this framework. The summary of critical computerised controls and process flow for each module has also been elaborated. This framework may assist software developers to understand the process of halal pharmaceuticals especially in the requirements phase of the software development lifecycle [12]. Some opportunities for further research include increasing the scope of study to other related pharmaceutical type of products as this research has only focused in the area of solid dosage manufacturing [12].

\section{ACKNOWLEDGMENTS}

I would like to thank Pharmaniaga Manufacturing Berhad's warehouse and procurement personnel for their cooperation and contribution in this research paper.

\section{REFERENCES}

[1] Alserhan, B.A, 2010.,'Islamic Branding: A Conceptualization of related terms', Brand Management, Vol 18, No. 1, pp $34-49$.

[2] Wingate, G. 2004(ed), 'Computer Systems Validation Quality Assurance, Risk Management, and Regulatory Compliance for Pharmaceutical and Healthcare Companies', Florida: CRC Press LLC.

[3] Wilson, J.A.J., Liu, J. 2010, 'Shaping the Halal into a brand?', Journal of Islamic Marketing, Vol. 1, No. 2, pp. 107-123.

[4] Noordin, N, Noor, N, Hashim, M, Samicho, Z, 2009. 'Value Chain or Halal Certification System: A Case of the Malaysia Halal Industry', European and Mediterranean Conference on Information Systems, 1314 July 2009, Izmir. 
[5] Janis, Z.M., 2004, 'Malaysia Standard MS1500:2004 Halal Food - Production, Preparation, Handling and Storage - General

Guidelines (First Revision)', SIRIM Standards \& Quality News, Vol 11 No. 4., pp 2-3., Shah Alam: SIRIM Berhad.

[6] Department of Standards Malaysia 2011, MS 2424:2010 (P) : Halal Pharmaceuticals - General Guideline. Shah Alam: SIRIM Berhad.

[7] Shatar, L. A. A., 2010, 'CCM : Championing Halal Pharmaceuticals', World Halal Research Summit 2010, Kuala Lumpur.

[8] Lembaga Pengkajian Pangan, Obat-obatan dan Kosmetika,Majelis Ulama Indonesia (LPPOM MUI) 2008, 'General Guidelines of Halal Assurance System', Jakarta: LPPOM MUI.

[9] Hisham, D. M., 2010, 'The Halal Concept and Identifying the Critical Points in the Halal Value Supply Chain', CCMB Suppliers Halal Awareness Seminar, Available at: http://www.hdcglobal.com [Accessed on 4 April 2013].
[10] Pery, 1996, ‘A bitter pill to swallow', Manufacturing Engineer, April 1996. Vol 4(1), London: IET Journals amd Magazines.

[11] U.K. Department of Health and Social Security, 1989, The Application of GLP Principles to Computer Systems, GLP Monitoring Unit. London: United Kingdom Compliance Programme.

[12] Raja Ikram, R. R., 2013, 'Halal Computerised Systems Framework for the Halal Pharmaceuticals', Unpublished masters dissertation, Malacca: Universiti Teknikal Malaysia Melaka.

[13] Raja Ikram, R. R., Abd Ghani, M. K. and Abd. Samad, H.B., 2012, 'Halal Computer Systems Validation Quality Assurance, Risk Assessment and Regulatory Compliance For The Pharmaceutical and Healthcare Industry', 3rd International Conference on Engineering \& ICT (ICEI2012), April 4-6, 2012, Melaka, Malaysia.

[14] The Pharmaceutical Inspection Convention and Pharmaceutical Inspection Co-operation Scheme (PIC/S), 2007, ' Guide to Good Manufacturing Practice for Medicinal Products Annexes, Annexe 11 . Computerised Systems', PIC/s Secretariat, PE 009-6. Geneva: PIC/S. 